\title{
Recent developments in Canine Cognitive Dysfunction Syndrome.
}

\author{
Alejandro Seisdedos Benzal and Alba Galán Rodríguez ${ }^{1}$
}

Abstract

Canine Cognitive Dysfunction Syndrome (CCD) is a neurodegenerative disease affecting aging dogs. CCD is an underdiagnosed disease that involves at least $14 \%$ of geriatric dogs, but apparently less than $2 \%$ of diseased dogs are diagnosed. There are several physiopathological similarities between Alzheimer disease (AD) and CCD, developing amyloid- $\beta$ deposits in brain parenchyma and blood vessels, brain atrophy and neuronal loss. The clinical signs lead to behavioural changes. They are unspecific and could appear as soon as seven years of age, but are more relevant in senior dogs. The abnormal behaviour could be classified following the acronym DISHA: Disorientation in the immediate environment; altered Interactions with humans and other animals; Sleep-wake cycle disturbances; House-soiling; and changes in Activity levels. There is no specific diagnostic test or biomarker to demonstrate the presence of CCD; therefore, it is often assessed by ruling out other diseases that may cause similar behavioural changes. Veterinarians have to be able to make an accurate account of veterinary history asking for abnormal behaviour that could be misreported by the owners. CCD is a neurodegenerative disorder that cannot be cured. It is possible to delay the progression of the clinical signs and improve the quality of life of patients, but like in AD, the progression of the illness will depend on the individual. There are three treatment pathways, which could be used in combination: drug therapy to improve cognition and reduce anxiety, antioxidant diet and nutraceutical supplements to reduce the progression of the illness, and finally, environmental enrichment to maintain brain activity. The aim of this review article is to contribute to the knowledge of the illness, presenting recent advances in the pathophysiology, diagnosis and treatment of the disease.

Pet Behaviour Science | 2016, Vol. 1,47 - 59

Alejandro Seisdedos Benzal and Alba Galán Rodríguez

1. Department of Medicine Paper Review and Animal Surgery.

University of Cordoba

Email:

ale_6d2bz@hotmail.com

Spain

Keywords:

Abnormal behaviour; Alzheimer;

cognitive disorder; cognitive

dysfunction syndrome; dog

\section{HIGHLIGHTS}

Although canine cognitive dysfunction syndrome is an underdiagnosed disease, research in this field is growing and clinical advances have been made, and as a result, this syndrome is becoming more common.

CCD causes a decline in quality of life for both the dog and the owner.

It is necessary to improve the overall knowledge about this condition in order to make an early diagnosis to slow its progression. 
This review article presents the recent advances in diagnosis and treatment of the illness and contributes to our understanding of the syndrome.

\section{INTRODUCTION}

Aging is a natural process that affects every cell of the body including neurons. As animals age, different illnesses that could compromise their quality of life (QOL) appear. Both human and veterinary medicine have increased the longevity of people and pets, respectively. Therefore, the development of neurodegenerative diseases is becoming more frequent (Landsberg et al. 2012). The relationship between clinical signs and physiopathology in Alzheimer disease $(\mathrm{AD})$ and canine cognitive dysfunction syndrome (CCD) makes the dog an excellent animal model for the understanding of AD (Cummings et al. 1996; Fast et al. 2013).

Canine $\mathrm{CCD}$ is an age-related neurodegenerative illness that generally affects dogs over seven years of age and is characterized by gradual cognitive decline and increasing brain disorders (Landsberg 2005; Landsberg et al. 2011, Laflamme 2012; Nagasawa et al. 2014). The age of onset of the clinical signs depends on the breed according to their life span differences. Despite the fact that the prevalence did not differ between breeds (Salvin et al. 2006), smaller breeds have a longer life span than the larger ones, thus it is possible to recognize more clinical signs of CCD in small breeds (Vite and Head 2014; Schmidt et al. 2015). CCD prevalence is reported to range from 14\% (Salvin et al. 2006) to $22 \%$ (Azkona et al. 2009). In a study of 497 dogs from eight to 19 years, Salvin and colleagues (2006) recruited owners to an internet-based survey. This 84-item questionnaire was used to estimate the incidence of CCD. The survey included questions about activity levels, behaviour, phobias, eating and drinking habits, management and health. They found an overall prevalence of $14.2 \%$, but it could be up to $41 \%$ in dogs older than 14 years. Consequently, Salvin et al. (2006) suggested that the prevalence seems to be higher in older dogs. Azkona et al. (2009) used 325 geriatric dogs to describe the prevalence of the disease. They used phone interviews to gather information about four behavioural categories related to cognitive impairment: sleep-wake cycles, social interaction, learning and house training and signs of disorientation. Regardless of breed, the prevalence seems to be higher in females than in males. Prevalence is also reportedly higher in neutered males, than entire males (Landsberg et al. 2011).

There are numerous nonspecific clinical signs of CCD, like disturbance of the sleep/wake cycle, changes in social interactions with people, urinary and faecal incontinence, disorientation in well-known places, hearing loss, and excessive vocalization among others (Dewey 2008, p. 123; Nagasawa et al. 2014). Because of these nonspecific clinical signs and the fact that the owners usually think that the behavioural changes of their pets are due to the typical changes caused by aging, it is often difficult to make an accurate and early diagnosis of CCD. Recent studies have focused on the development of diagnostic tools based on food searching or problem solving tasks. There are also recent advances in the knowledge of the physiopathology of the aging brain, and about new treatments with drugs, diets and environmental enrichment (Landsberg et al. 2011; Laflamme 2012; Landsberg et al. 2012; González-Martínez et al. 2013; Vite and Head 2014).

It is documented that cognitive impairment in older dogs can be a challenging problem, both for the animal and for the owners. The high percentage of geriatric cognitive impaired dogs and the reduction in dog's QOL suggest a better knowledge of CCD is necessary (Landsberg et al. 2011). The aim of this review is to compile the recent advances in physiopathology, diagnosis and treatment options for CCD.

\section{PHYSIOPATHOLOGY}

There are several histopathologic similarities between human brains affected by $\mathrm{AD}$ and dog brains suffering from CCD. In both diseases, the aged brain develops an abnormal $\beta$-amyloid $(A \beta)$ deposit in brain parenchyma and blood vessels, neuronal loss and hyperphosphorylated tau protein (HTP) (Schmidt et al. 2015). $A \beta$ is a protein produced by the degradation of amyloid precursor protein (APP) (Vite and Head 2014). In the aging dog brain the deposits present as diffuse plaques in cortical regions, and tend to appear from eight years of age (Landsberg et al. 2012; Fast et al. 
2013; Schmidt et al. 2015). The prefrontal cortex is the first area affected, followed by the temporal cortex, the hippocampus and the occipital cortex.

Regardless of position, the amount and extent of $A \beta$ deposits are correlated with the degree of cognitive impairment and leads to oxidative damage (Fast et al. 2013; Vite and Head 2014; Romanucci and Della Salda 2015; Schmidt et al. 2015). In addition, a local inflammatory reaction has been found around $A \beta$ deposits in both humans and dogs (Schmidt et al. 2015). $\mathrm{A} \beta$ deposits are also found in brain blood vessels in $\mathrm{AD}$ and CCD. Cerebrovascular amyloid angiopathy (CAA) is related to cognitive impairment in both humans and dogs (Romanucci and Della Salda 2015). The occipital cortex is the main affected area and these deposits could disrupt the blood-brain-barrier and cause microhemorrhages (Vite and Head 2014).

The brain consumes $20 \%$ of the total body's oxygen and is very susceptible to oxidative damage due to the high percentage of polyunsaturated fatty acids and the lower levels of endogenous antioxidant activity (Head 2008). The metabolic process of the cells causes the release of reactive oxygen species (ROS) that lead to oxidative damage to proteins, lipids, DNA and RNA (Head 2008). The production of ROS depends on the mitochondria (Romanucci and Della Salda 2015); therefore, a mitochondrial dysfunction could cause the overproduction of ROS. This, together with a lesser activity of antioxidants enzymes in the aged canine or in the neurodegenerative disease could lead to oxidative damage, $A \beta$ deposition and cognitive dysfunction (Dowling and Head 2012; Davis and Head 2014; Vite and Head 2014; Romanucci and Della Salda 2015).

Iwata and colleagues (2005) described the $A \beta$ catabolism and found that an imbalance between production and clearance of $A \beta$ could provoke the accumulation of $A \beta$ in the brain. $A \beta$ could be eliminated by two mechanisms: active transport through the blood brain barrier and enzymatic degradation by peptidases like neprilysin (NPL) (Canudas et al. 2014). In the brain areas in which the $\mathrm{A} \beta$ deposits are more frequent, NPL is expressed in lower levels than areas with lesser amounts of $A \beta$ accumulation (Reilly 2001). Canudas et al. (2014) found that the expression of NPL was five times higher in the cognitive unimpaired dogs than in the cognitive impaired dogs. This suggests that NPL could protect against CCD.

In a recent study, Schmidt and colleagues (2015) provided the first description and quantification of pyroglutamyl $A \beta(p E 3 A \beta)$ in the canine brain. The $\mathrm{pE} 3 \mathrm{~A} \beta$ is a peptide derived from $\mathrm{A} \beta$ peptides that suffers from $\mathrm{N}$-terminal truncation and subsequent cyclization of N-terminal glutamate (HartlageRübsamen et al. 2011). This peptide encourages the accumulation of $A \beta$ facilitating the onset of CCD. The ventral hippocampus and entorhinal cortex of aged dogs' brain seem to be more affected by $p E 3 A \beta$ deposits; the location of these deposits correlates with clinical signs of CCD, such as disorientation and memory loss (Schmidt et al. 2015).

In human medicine there is a documented relationship between HTP and cytotoxicity of A $\beta$ deposits (Schmidt et al. 2015). In a study by Schmidt et al. (2015), only one out of 24 dogs displayed formation of neuro fibrillary tangles of HTP. Therefore, research reinforces that the $\mathrm{A} \beta$ deposits and the HTP are two independent processes in the aged canine brain (Head 2002; Schmidt et al. 2015).

Other physical pathological changes in CCD are different processes related to brain atrophy, such as: thinning of the cerebral cortex and subcortical white matter; widened sulci; marked ventriculomegaly; meningeal calcification; demyelination; increased lipofuscin; neuroaxonal degeneration; and apoptotic bodies (Laflamme 2012; Landsberg et al. 2012; Vite and Head 2014).

Brain atrophy may be due to neuronal loss. In the brain of dogs, new neurons are produced continually from progenitor cells placed in specific brain regions such as the dentate gyrus of the hippocampus. In a previous study, Siwak-Tapp and colleagues (2007) found a $90 \%$ to $96 \%$ decline in neurogenesis in the hippocampus of aged beagles. This suggests that the neuronal loss in the brain atrophy process could be related to cognitive performance in aged dogs. According to Pan and colleagues (2012), reduction in neurogenesis could be caused by the lesser extent of progenitor cell 
proliferation and the shorter survival of the neurons. Alterations in neurochemical systems such as the cholinergic, glutaminergic, dopaminergic and GABAergic neurotransmitter systems, with reduced neuronal and synaptic function have also been observed (Landsberg et al. 2012).

All these brain changes could contribute to the primary clinical signs of CCD like memory loss, alteration in spatial orientation, and alteration in REM sleep (Landsberg et al. 2012).

\section{CLINICAL SIGNS}

When dogs are aged seven years old or older, we consider that they are senior canines at risk of developing an age-related health problem (Laflamme 2012). Although clinical signs of CCD may appear at seven years old, these become more relevant as dogs age. Nevertheless, owners often overlook CCD signs, dismissing them as normal aging. Delay in the recognition of cognitive impairment could be due to the fact that the owners sometimes do not realize subtle signs of behavioural changes or associate the changes with the advanced age of their pets. It is very important to consider the complete veterinary history and to question dog owners/handlers about behavioural changes that could be indicative of cognitive impairment when diagnosing the condition (Landsberg et al. 2012).
Vite and Head (2014) describe a case of CCD in an 11 year old female Border Collie used on a farm as a livestock herding dog. According to her owner, when the dog reached 11 years, she was almost deaf, had begun to show some confusion with commands and had lost interest in pursuing sheep. Over the next two years the hearing loss progressed and her behaviour was perceived by the owner as stubbornness. She started to stalk the other resident dog and began pacing, panting, and showing signs of anxiety when her owner was not at home. She was no longer making eye contact with people and sometimes she lost the route that she had previously followed daily. She was euthanized at 14 years old and an extensive diffuse $A \beta$ deposit was found in the dentate gyrus and prefrontal cortex.

All the physiopathological changes in CCD cause several clinical signs that are classified following the acronym DISHA (Table 1): Disorientation in the immediate environment, altered interactions with humans and other animals, sleep-wake cycle disturbances, house-soiling, and changes in activity levels (Manteca 2011; González-Martínez et al. 2013). In addition, it is important to consider that there is individual variability between aged dogs in terms of clinical signs for the same pathology (Nagasawa et al. 2014). Despite this, in a study by Mariotti et al. (2009), aggression was the most reported clinical sign (53\%), followed by fear and anxiety reported in a much lower

\begin{tabular}{|cccc|}
\hline D & $\begin{array}{c}\text { Cognitive } \\
\text { impairment }\end{array}$ & Clinical signs & $\begin{array}{c}\text { Diseases that cause clinical } \\
\text { signs similar to CCD }\end{array}$ \\
\hline I & $\begin{array}{c}\text { Disorientation in the } \\
\text { immediate } \\
\text { environment }\end{array}$ & $\begin{array}{c}\text { Vocalizing, fear or phobia, } \\
\text { hiding behaviour }\end{array}$ & Hearing loss, visual loss \\
& $\begin{array}{c}\text { Altered Interactions } \\
\text { with humans and } \\
\text { other animals }\end{array}$ & $\begin{array}{c}\text { Stops jumping up during } \\
\text { greeting, avoidance of owner, } \\
\text { growling, aggressiveness }\end{array}$ & Arthritis, arthrosis, epilepsy, \\
neuropathic pain
\end{tabular}

Table 1. Clinical signs of CCD that can be classified following the acronym DISHA 
proportion of subjects. To summarise, in cases of suspected CCD, it is essential that the veterinarian assesses for clinical signs related to DISHA.

Dogs with CCD may also express signs of anxiety; however, these may also appear with pain or relate to other systemic illnesses. These signs could be new behavioural patterns like eliminating in unusual places at home, cessation of jumping behaviour when greeting people, avoidance of the owner or home residents, unusual growling or aggressiveness, excessive panting, yawning, nose licking, or momentary immobilization. Social alterations related to anxiety, such as decreased play-time with people and other pets, decreased interest in toys, altered quality of sleep, and hiding behaviour may also be relevant. When signs of anxiety appear at night it may pose a significant problem due to sleep disruption of the home residents, thus the relationship between owner and pet may become negatively affected (Landsberg et al. 2011).

Nearly all of the clinical signs in the DISHA suite could be confused with different diseases. In this way, veterinarians have to be cautious when diagnosing CCD without ruling out other pathologies. Disorientation in the immediate environment may be caused by hearing loss as a result of aging or chronic otitis, visual loss because of the development of cataracts, glaucoma or retinal detachment among others (Bernardini 2010, p. 30, 36). Changes in interactions with humans or other animals could be due to some painful illnesses. It is frequent that senior dogs developing arthritis and/or arthrosis are reluctance to move and play with other dogs, and may even become aggressive in an attempt to avoid contact (Nelson and Couto 2009, p. 1121). Epileptic dogs can show an abnormal behaviour during the pre- and postseizure period (De Risio and Platt, 2014, p.39).

The allodynia or hypersensitivity to skin pressure due to neuropathic pain could also deteriorate the interaction with humans. In this case, when owners caress the affected region the dog may even yell or moan due to pain (Grubb 2010). Sleep-wake cycle disturbances and house-soiling are also related to systemic illnesses, like renal or hepatic failure. The development of acute or chronic kidney disease is common in geriatric dogs. These diseases may provoke changes to urination patterns, pain and a reduction on the activity of the dog (Nelson and Couto, p. 491, 617).

There are several disorders that may change the normal activity of the dog. Metabolic disorders like hypothyroidism and hypoadrenocorticism could cause, among other symptoms, lethargy, reluctance to move and tendency to gain weight (Ettinger and Feldman 2010). Cardiovascular disorders like dilated or hypertrophic cardiomyopathy, heart blockage or valve heart disease, among others, could cause a reluctance to move or quick fatigue during exercise (Ettinger and Feldman 2010,).

To the authors' knowledge, DISHA constitutes the best model to explain the clinical signs of CCD since it puts together the main behavioural changes of a cognitively impaired dog. Anxiety might be a new letter to add to the acronym but we consider that all the behavioural changes of DISHA could cause some discomfort and anxiety to the dog.

\section{DIAGNOSIS}

Salvin and colleagues (2011) conducted an epidemiological study surveying 497 dogs ranging from eight to 19 years. The overall prevalence of CCD was calculated based on owner reports to be $14.2 \%$; however, only $1.9 \%$ had a presumptive diagnosis of CCD from a veterinarian. Underdiagnosis may be frequent due to the lack of a specific diagnostic tool and the unspecific symptoms. As commented previously, some owners are not able to report subtle behavioural changes in their pets or may have dismissed them as typical aging processes. Therefore, veterinarians must be active in asking about any changes or abnormalities to the dog's behaviour, asking specifically for disorientation in daily life, longer sleeping time along the day, loss of house training and house-soiling. It is also important to know the normal behaviour of the dog during its life to assess any potential abnormal changes in behaviour due to an underlying disease. There are several types of chronic illnesses that may provoke changes in canine behaviour. Orthopaedic disease could cause pain, cardiovascular impairment may lead to reluctance to exercise and metabolic disorders could reduce the normal activity of the animal or increase aggressiveness. To ensure accuracy, 
the diagnosis of CCD should be made following exclusion of all these diseases (Landsberg et al. 2011).

Therefore, it is necessary to make an exhaustive clinical exam (physical, neurological, ophthalmologic, orthopaedic and ethological examination) to assess behavioural changes related to any physical illness (Landsberg et al. 2012). Intracranial pathologies related to behavioural changes, such as brain tumours, are more frequent in aged dogs. Endocrine disorders could cause irritability, lethargy and aggressiveness. Metabolic disorders like hepatic or renal failure lead to an altered mentation and house-soiling. Orthopaedic, gastrointestinal, urogenital and dermatological diseases likewise neuropathic pain could cause severe pain conditions that may provoke behavioural changes. Cardiovascular diseases are related to restless (Landsberg et al. 2011). In addition, it is common to find two or more of these diseases in geriatric patients. Knowledge of existing and/or previous medications and treatments is also important, and possible cognitive impairment associated with these drugs should be ruled out. Steroids have been shown to be associated with changes to eating, drinking and urination as well as nervousness and aggression. In addition, pain medication can sometimes cause sedation (Landsberg et al. 2012).

When all these pathologies have been ruled out it is important to carry out an owner-based observational questionnaire to assess the cognitive function of the patient (González-Martínez et al. 2013). Nielson and colleagues (2001), carried out a study with 180 dogs from 11 to 16 years old, using a questionnaire including items related to four categories of cognitive impairment (disorientation, altered social interactions, disturbed sleep-wake cycle and house training). They assessed the severity of the cognitive impairment depending on the number of categories affected and the number of new behavioural changes found in each category. To the authors' knowledge, it could be essential to include items related to all categories of DISHA in any ownerbased observational questionnaire. Because there is individual variability in the presentation of clinical signs and, due to the fact that DISHA includes all the behavioural changes known to be found in a dog with CCD, a questionnaire based on DISHA could be an appropriate diagnostic tool.
González-Martínez et al. (2013), searched for a more objective diagnostic procedure than these owner-based observational questionnaires. They assessed the effectiveness of two simple tasks (a food searching task [FS] and a problem solving task [PS]) administered in a clinical setting in 87 dogs. They found differences in the two tasks between the cognitively impaired group and the young-middle aged group. The younger dogs comprising the second group were able to find and obtain the food more quickly than their aged counterparts in the cognitively impaired group. In addition, some dogs in the latter group did not even attempt to search for the food. These assessment tasks could help in the accurate diagnosis of CCD.

\section{TREATMENT}

It is important for veterinarians to advise owners of dogs diagnosed with CCD that it is a neurodegenerative disorder that cannot be cured, although it is possible to delay the progression of the clinical signs and improve the QOL of the dog. However, as in AD, the advancement of the illness is dependent on the individual (Landsberg et al. 2011). Current treatments tend to combine specific diets, environmental enrichment and drugs, obtaining better success and improving pets' QOL. The sooner treatment begins, the better the response, therefore it is important to make an early diagnosis (Landsberg et al. 2012).

\section{Nutritional Treatment}

In human medicine, there are several studies about the best diet option for the treatment of AD. The combination of various antioxidants seems to be more efficacious as part of the diet than as a single nutraceutical supplementation (Dowling and Head 2012). In veterinary medicine, studies shown that an antioxidant diet, in addition to some dietary supplements, is the best nutritional therapy (Laflamme 2012; Landsberg et al. 2012)(Table2). 


\begin{tabular}{|c|ccc|}
\hline \multirow{4}{*}{ Treatment } & Product & Cognitive benefits & $\begin{array}{c}\text { DISHA } \\
\text { categories } \\
\text { improved }\end{array}$ \\
\hline \multirow{4}{*}{ Diet } & $\begin{array}{c}\text { Antioxidant diet (Vitamins A, C, E, } \\
\text { selenium, Zinc, L-carnitine, Lipoic } \\
\text { acid) }\end{array}$ & $\begin{array}{c}\text { Spatial attention, visual } \\
\text { discrimination and } \\
\text { learning ability }\end{array}$ & D-H \\
\cline { 2 - 4 } & Diet supplemented with MCT & $\begin{array}{c}\text { Spatial attention, visual } \\
\text { discrimination and } \\
\text { learning ability }\end{array}$ & D-H \\
\hline \multirow{4}{*}{ Nutraceuticals } & Phosphatidylserine & $\begin{array}{c}\text { Social interactions, } \\
\text { house soiling and } \\
\text { orientation }\end{array}$ & D-I-H \\
\cline { 2 - 4 } & S-adenosyl-L-methionine & Activity and awareness & A \\
\cline { 2 - 5 } & Apoaequorin & Learning and attention & D-H \\
\cline { 2 - 5 } & $\begin{array}{c}\text { Docosahexaenoic acid (DHA) and } \\
\text { eicosapentaenoic acid (EPA) }\end{array}$ & Learning and attention & D-H \\
\cline { 2 - 5 } & Alpha-casozepine & Anxiety and aggression & I \\
\hline
\end{tabular}

Table 2. Diet and dietary supplementation used in CCD (Landsberg et al. 2012).

Initially, the nutrition of the pet's diet must be evaluated because of the changes in the nutritional requirements associated with aging. Maintenance energy requirements decrease about $25 \%$ in dogs greater than seven years of age and brain glucose metabolism is also reduced. Thus it is mandatory to adapt the current diet to their current nutritional requirements (Laflamme 2012). Dowling and Head (2012) used an antioxidant diet formulated with vitamins $\mathrm{A}, \mathrm{C}$ and $\mathrm{E}, \mathrm{L}$-carnitine, lipoic acid, zinc, selenium and dehydrated fruits and vegetables (spinach flakes, tomatoes, grape pomace, carrots and citrus pulp in a $1 \%$ proportion each). They proved that reduced oxidative stress leads to cognitive benefits. They used 48 senior beagles divided in four groups: two control diet groups, one with and the other without behavioural enrichment (groups 1 and 2), and other two groups of antioxidant diets with and without behavioural enrichment respectively (groups 3 and 4). There were significant improvements over a two week period related to spatial attention, visual discrimination and learning ability in the groups fed with antioxidant diet, especially in the group with environmental enrichment. In addition, reduced oxidative damage and increased endogenous antioxidant activity were found in groups 3 and 4 in the study.

Glucose is the main energy source of neurons. However, glucose metabolism is reduced with aging and other energy sources are needed to maintain neurons' metabolism (Pan 2011; Laflamme 2012). Fatty acids derived from MCT could provide up to $20 \%$ of brain energy request. For instance, lactate and ketones cross the blood-brain barrier and serve as energy source (Laflamme 2012; Landsberg et al. 2012). Pan and colleagues (2010) found significant improvement in cognitive function in dogs fed with medium chain triglycerides. It has been proven that diets supplemented with this type of lipid also reduce levels of APP and A $\beta$ deposits and improve mitochondrial function (Taha et al. 2009). Nowadays, we can find numerous commercial diets containing medium chain triglycerides and antioxidants such as Hill's Pet Nutrition b/d and Purina One Vibrant Maturity 7+ Senior.

Due to the possibility of two or more concomitant diseases in senior dogs, often it is not possible to make changes in the diet. In this case the use of single nutraceuticals can be an alternative. Phosphatidylserine is a phospholipid that improves social interactions, house soiling and orientation in dogs (Heath et al. 2007). In a study of aged beagles fed with phosphatidylserine, Gingko biloba, vitamin E and pyridoxine an improvement in their short term memory was observed (Dowling and Head 2012). Sadenosyl-L-methionine increases endogenous production of antioxidant glutathione and improves neural conduction enhancing executive function (Landsberg et al. 2012). Apoaequorin is a protein that 
seems to have neuroprotection hallmarks in aging dogs. This protein improves learning and attention in laboratory trials (Milgram et al. 2011). Docosahexaenoic acid (DHA) and eicosapentaenoic acid (EPA) are two polyunsaturated omega-3 fatty acid present in fish oil that protects the normal neural functions. It is seen that these fatty acids decrease in AD but there are no data about the beneficial properties in CCD (Laflamme 2012). Galán and colleagues (2014) used a nutritional supplement (Aktivait ${ }^{\circledR}$, VetPlus) that includes $\mathrm{N}$-acetil cysteine, a-lipoic acid, Vitamins C and E, L-Carnitine, Co-enzyme Q10, and polyunsaturated fatty acids (PUFA, phosphatidylserine, DHA and EPA) in order to evaluate changes in cerebrospinal fluid after a 50-dayperiod of treatment. They found increased levels of glucose and sodium and lower levels of lactate and lactate/pyruvate ratio, suggesting an improvement in brain energy metabolism after dietary supplementation.

There are several studies about the beneficial effects of acetylcarnitine and lipoic acid in AD and CCD. Both of them enhance mitochondrial function reducing reactive oxygen species and also reducing oxidative damage. Nevertheless, when these two products are used in combination with antioxidant substances, the beneficial effects are not seen (Dowling and Head 2012). Alphacasozepine is a biopeptide from milk that is proved to reduce anxiety in rodents and it has been used as a nutraceutical compound to treat anxiety and behavioural disorders like aggression in dogs (Manteca 2011).

In summary, an antioxidant diet combined with nutraceuticals (MCT, phosphatidylserine, apoaequorin, DHA and EPA) improves cognitive impairment in dogs. This treatment enhances visuospatial function, learning ability and the ability to focus the attention.

\section{Environmental Enrichment}

It has been demonstrated that behavioural enrichment is protective against neuron loss in the hippocampus of dogs, improving all DISHA parameters (Dowling and Head 2012). The enrichment has to include physical exercise, social interactions and cognitive training (Romanucci and Della Salda 2015). Mental activity is an important component to maintain a good QOL.
Effective strategies to increase the attention of cognitively impaired dogs include the use food/treat puzzle toys, walks in new environments and to play games such as fetch and chase. In using environmental enrichment, it is also important to improve the comfort of the pet. New odour, tactile and sound cues could help the dog to orientate in the environment. If there is an increase in the urine frequency, it may be necessary to increase the number of walks or to put a toilet area inside home (Landsberg et al. 2012). When there are problems of night time waking and anxiety, it is important to improve dog's sleeping patterns. Owners should pet the dog when it is resting in its sleeping area, turn off the $\mathrm{TV}$, reduce noises and intensity of lights during the night, and place the dog's bed in its preferred resting area. A useful routine to enhance the sleeping time is to schedule a physical activity such as game playing, or a long walk to tire the dog, before to the dog's rest time (Landsberg et al. 2011).

\section{Drug Therapy}

The aim of the drug therapy is to restore the natural brain function and to slow the progression of the illness. Due to the fact that an inflammatory reaction around $\mathrm{A} \beta$ deposits exists, it has been proposed the use of anti-inflammatory drugs like carprofen $(4,5 \mathrm{mg} / \mathrm{kg} / 24 \mathrm{~h})$ (Dewey 2008, p. 126). There are several medications for the treatment of CCD (see Tables 3 and 4 for the main and complimentary drugs used in the treatment of CCD respectively).

Traditionally, the three drugs selegiline, nicergoline and propentofylline, have been used for the treatment of CCD. They confer beneficial effects in activity levels, improving catecholamines' levels in the cortex and also the blood flow to the brain. Propentofylline also increases spatial attention and it is effective treating dullness, lethargy and depression; whereas selegiline also enhances social interactions and sleep-wake cycles (Landsberg et al. 2012). However it is not possible to enhance all the DISHA categories by using these drugs alone (Landsberg et al. 2012).

There are other drugs such as adrafanil and modafinil, two noradrenergic-enhancing drugs, that improve locomotion and learning in dogs (Dewey 2008, p. 126). Inagawa and colleagues (2005) found that $\gamma$ - 
aminobutyric acid (GABA) improves QOL of cognitive impaired dogs. Different behavioural changes like whines, barks during the night and when the dog is home alone, wandering, and sleeping patterns were all effectively/moderately alleviated with the use of a test preparation containing GABA. A GABA-ergic drug that could be used for the treatment of CCD is gabapentin (Dewey 2008, p. 126; Landsberg et al. 2012). A recent study by Nagasawa and colleagues (2014) showed that $\mathrm{N}$-acetyl-D-mannosamine (ManNAc) alleviates clinical signs of CCD. Four out of the five dogs treated with ManNAc showed a permanent improvement in sleep quality.
These substances are often used to treat fears and phobias and can also help the dog to sleep better. Phenobarbital, diphenhydramine and trazodone may also be used for sleep support due to their sedative effect. It is recommended these drugs be given 30 minutes before sleeping (Landsberg et al. 2011).

Other clinical signs related to anxiety, such as noise and night phobias and separation anxiety, could be treated with buspirone, fluoxetine or tricyclic antidepressants. Nevertheless, the anticholinergic effects need to be taken into consideration (Jaggy 2010, p. 487, Landsberg et al. 2011).

Table 3. Maind drugs and doses for CCD treatment

\begin{tabular}{|c|c|c|}
\hline Drug and dose & Mechanism of action & $\begin{array}{l}\text { DISHA } \\
\text { categories } \\
\text { improved }\end{array}$ \\
\hline $\begin{array}{l}\text { Selegiline }{ }^{1} \\
0,5-1 \mathrm{mg} / \mathrm{kg} / 24 \mathrm{~h} \text { (in the } \\
\text { morning) }\end{array}$ & $\begin{array}{l}\text { Selective and irreversible inhibitor of monoamine oxidase B. Improves } \\
\text { the levels of catecholamines in the brain cortex, promotes free radical } \\
\text { scavenging and protects nerves from degeneration }\end{array}$ & I-S-A \\
\hline $\begin{array}{l}\text { Propentofylline } \\
2,5-5 \mathrm{mg} / \mathrm{kg} / 12 \mathrm{~h}\end{array}$ & $\begin{array}{l}\text { Metilxantine improves blood flow to the brain, inhibiting thrombus } \\
\text { formation and reducing peripheral vascular resistance. It enhances } \\
\text { nutrient input to brain cells and increases the production of adenosine, } \\
\text { a fundamental nucleoside for mitochondrial metabolism }\end{array}$ & D-A \\
\hline $\begin{array}{l}\text { Nicergoline } \\
0,25-0,5 \mathrm{mg} / \mathrm{kg} / 24 \mathrm{~h}\end{array}$ & $\begin{array}{l}\text { Improves brain blood flow and activates cerebral metabolism. There } \\
\text { are few studies about the effectiveness in the treatment of CCD. }\end{array}$ & $\mathbf{A}$ \\
\hline $\begin{array}{l}\text { Adrafinil }^{2} \\
20 \mathrm{mg} / \mathrm{kg} / 24 \mathrm{~h}\end{array}$ & Enhances the noradrenergic system & S-A \\
\hline$\underset{30 \mathrm{mg} / \mathrm{kg} / 24 \mathrm{~h}}{\mathrm{GABA}^{3}}$ & Inhibitory neurotransmitter & $\mathbf{S}$ \\
\hline $\begin{array}{l}\text { Gabapentin } \\
10-30 \mathrm{mg} / \mathrm{kg} / 8-12 \mathrm{~h}\end{array}$ & $\begin{array}{l}\text { Inhibition of the voltage-dependent calcium channels in the } \\
\text { presynaptic membrane decreasing the release of excitatory } \\
\text { neurotransmitters. }\end{array}$ & $\mathbf{S}$ \\
\hline $\begin{array}{l}\mathrm{N} \text {-acetyl-D- } \\
\text { mannosamine } \\
250 \mathrm{mg} / \mathrm{dog} / 24 \mathrm{~h}\end{array}$ & $\begin{array}{c}\text { An isomer and a precursor of sialic acids. These are the most } \\
\text { abundant terminal monosaccharides on glycoconjugates on } \\
\text { eukaryotic cell surfaces and are involved in a variety of cellular } \\
\text { functions }\end{array}$ & D-S \\
\hline
\end{tabular}

To the authors' knowledge, selegiline is the most useful drug in treating CCD (Jaggy 2010, p.485), however it is necessary to combine this with complimentary therapy in order to enhance all the behavioural changes associated to the physiopathology of the syndrome. Benzodiazepines are useful to treat sleep-wake cycle disturbances and anxiety because of their sedative and short-acting anxiolytic effects (Landsberg et al. 2011).
There is some controversy surrounding the use of statins for the treatment of CCD. Atorvastatin is a selective inhibitor of HMG-CoA reductase that acts lowering cholesterol levels and reducing $A \beta$ deposits. This drug has been used in human medicine reducing the risk of developing AD. However, it has been shown that atorvastatin reduces levels of coenzyme Q10 (CoQ10), a mitochondrial electron transporter and a 
powerful cellular antioxidant. Low levels of CoQ10 in the brain could be related to cognitive impairment (Martin et al. 2011). As seen in Martin and colleagues (2011) study, serum CoQ10 was significantly lower in atorvastatin-treated dogs. Therefore, more studies are needed to clarify the relationship between atorvastatin and CoQ10 and to determine the effectiveness of a combined treatment with atorvastatin and CoQ10 oral supplementation.

In a recent study, Bosch and colleagues (2015) developed an anti-A $\beta$ immunotherapy that modified the equilibrium between soluble and insoluble $A \beta$ in aged canines. In the immunized group, the amyloid plaques were smaller and less compact than those of the unimmunized group.

Among natural products that could help reduce anxiety and improve QOL for canine with $\mathrm{CCD}$, the valerian root, honokiol, berberine extracts, $\alpha$-casein, suntheanine, lavender essential oils, and a pheromone collar have been shown to be useful (Dewey 2008, p. 126; Landsberg et al. 2011).

To conclude, it is important to emphasise the need to use a combined therapy to treat CCD. According to DISHA, D and $\mathrm{H}$ parameters are specially improved with the nutritional treatment using an antioxidant or MCT enriched diet (I and A parameters could be also improved with an alpha-casozepine and S-adenosyl-Lmethionine supplementation, respectively). S and $\mathrm{A}$ parameters and anxiety could be enhanced by using different drugs. Finally, environmental enrichment helps in all the DISHA categories but especially in I parameter. The stimulation of mental activity along with physical exercise, cognitive training and games, improves social interactions with both humans and other animals.

\section{SUMMARY}

CCD is an underdiagnosed neurodegenerative disease that affects a high proportion of the aged canine population. The number of unspecific clinical signs makes it difficult to diagnose and there are no specific biomarkers of the illness. Therefore, the veterinarian has to rule out other diseases and medical treatments that may cause behavioural changes associated with the acronym DISHA. There are numerous choices for the treatment of CCD but some of these require more research to clarify their effectiveness. However, the best treatment option we currently know of is to combine drug and nutritional therapy with an environmental enrichment program to improve the QOL of both the owners and the canines.

\begin{tabular}{|c|c|c|}
\hline Drug and dose & Mechanism of action & $\begin{array}{l}\text { DISHA } \\
\text { categories } \\
\text { improved }\end{array}$ \\
\hline Phenobarbital $^{1}$ & $\begin{array}{l}\text { Enhancement of post-synaptic neuronal inhibition by } \\
\text { increasing responsiveness to GABA }\end{array}$ & S and anxiety \\
\hline $\begin{array}{c}\text { Diphenhydramine } \\
2-4 \mathrm{mg} / \mathrm{kg} / 8-12 \mathrm{~h}\end{array}$ & Serotonin reuptake inhibitor & $\mathbf{S}$ \\
\hline $\begin{array}{l}\text { Trazodone }{ }^{2} \\
\text { 2-5mg/kg as needed up to } 8-10 \\
\mathrm{mg} / \mathrm{k} / 8-12-24 \mathrm{~h}\end{array}$ & Serotonin 2A antagonist/ reuptake inhibitor & Anxiety \\
\hline$\underset{0,5-2,2 \mathrm{mg} / \mathrm{kg} / 6-8-12 \mathrm{~h}}{\text { Diazepam }^{3}}$ & \multirow{3}{*}{$\begin{array}{l}\text { All benzodiazepines potentiate the effects of GABA by } \\
\text { increasing the affinity of the receptors for the } \\
\text { neurotransmitter at the GABA-A receptors }\end{array}$} & \multirow{3}{*}{ S and anxiety } \\
\hline$\underset{0,02-0,1 \mathrm{mg} / \mathrm{kg} / 6-8-14 \mathrm{~h}}{\underset{\text { Alprazolam }}{3}}$ & & \\
\hline $\begin{array}{c}\text { Oxazepam } \\
0.2-1.0 \mathrm{mg} / \mathrm{kg} / 12-24 \mathrm{~h}\end{array}$ & & \\
\hline $\begin{array}{c}\text { Buspirone }{ }^{4} \\
1 \mathrm{mg} / \mathrm{kg} / 24 \mathrm{~h}\end{array}$ & Selective serotonin agonist & \\
\hline $\begin{array}{l}\text { Fluoxetine }^{5} \\
1 \mathrm{mg} / \mathrm{kg} / 24 \mathrm{~h}\end{array}$ & Selective serotonin reuptake inhibitor & I and anxiety \\
\hline
\end{tabular}

Table 4. Complimentary drugs and doses used in the treatment of CCD 


\section{REFERENCES}

Azkona, G., García-Belenguer, S., Chacón, G., Rosado, B., León, M., and Palacio, J. 2009. Prevalence and risk factors of behavioural changes associated with agerelated cognitive impairment in geriatric dogs. Journal of Small Animal Practice 50: 87-91.

Bernardini, M. 2010. Esame neurologico. In Neurologia del Cane e del Gatto, 30-69, ed. M. Bernardini. Milano: Poletto Editore.

Bosch, M.N., Pugliese, M., Andrade, C., Gimeno-Bayón, J., Mahy, N., and Rodríguez, M.J. 2015. Amyloid- $\beta$ immunotherapy reduces amyloid plaques and astroglial reaction in aged domestic dogs. Neurodegenerative Diseases 15(1): 24-37.

Canudas, J., Insua, D., Sarasa, L., González-Martínez, Á., Suárez, M.L., Santamarina, G., Pesini, P., and Sarasa, M. 2014. Neprelysin is poorly expressed in the prefrontal cortex of aged dogs with canine cognitive dysfunction syndrome. International Journal of Alzheimer 's Disease 2014.

Cummings, B.J., Head, E., Ruehl, W., Milgram, N.W., and Cotman, C.W. 1996. The canine as an animal model of human aging and dementia. Neurobiology of Aging 17: 259-268.

Davis, P.R. and Head, E. 2014. Prevention approaches in a preclinical canine model of Alzheimer's disease. Frontiers in Pharmacology 5: 47.

De Risio, L. and Platt, S. 2014. Classification of seizures and epilepsies. In Canine and Filine Epilepsy, 39, ed. J. Killick. Croydon, London, United Kingdom: CAB International.

De Risio, L. and Platt, S. 2014. Phenobarbital. In Canine and Filine Epilepsy, 374, ed. J. Killick. Croydon, London, United Kingdom: CAB International.

Dewey, C.W. 2008. Encephalopathies: Disorders of the brain. In $A$ Practical Guide to Canine and Feline Neurology, 115-220, ed. C.W. Dewey. Ames, Iowa: Iowa State University Press.
Dowling, A.L.S. and Head, E. 2012. Antioxidants in the canine model of human aging. Biochimica et Biophysica Acta-Molecular Basis of Disease 1822: 685-689.

Ettinger, S.J. and Feldman E.C. 2010. Endocrine disorders. In Textbook of Veterinary Internal Medicine, 1711-1873, ed S.J. Ettinger and E.C. Feldman. St. Louis, Missouri: Saunders Elsevier.

Ettinger, S.J. and Feldman E.C. 2010. Pathophysiology of Heart Failure. In Textbook of Veterinary Internal Medicine, 1143-1158, ed S.J. Ettinger and E.C. Feldman. St. Louis, Missouri: Saunders Elsevier.

Fast, R., Rodell, A., Gjedde, A., Mouridsen, K., Alstrup, A.K., Bjarkam, C.R., West, M.J., Berendt, M., and Moller, A. 2013. PIB fails to map amyloid deposits in cerebral cortex of aged dogs with canine cognitive dysfunction. Frontiers in Aging Neuroscience 5: article number 99.

Galán, A., Carletti, B.E., Morgaz, J., Granados, M.M., Mesa, I., Navarrete, R., Lombardo, R., Martínez, C.M., and Martín-Suárez, E.M. 2014. Comparative study of select biochemical markers in cerebrospinal fluid of healthy dogs before and after treatment with nutraceuticals. Veterinary Clinical Pathology 43(1): 72-77.

González-Martínez, Á., Rosado, B., Pesini, P., GarcíaBelenguer, S., Palacio, J., Villegas, A., Suárez, M.L., Santamarina, G., and Sarasa, M. 2013. Effect on age and severity of cognitive dysfunction on two simple tasks in pet dogs. The Veterinary Journal 198: 176-181.

Grubb, T. 2010. Chronic neuropathic pain in veterinary patients. Topics in Companion Animal Medicine 25(1): 4552.

Hartlage-Rübsamen, M., Morawski, M., Waniek, A., Jäger, C., Zeitschel, U., Koch, B., Cynis, H., Schilling, S., Schliebs, R., Demuth, H.U., and Robner, S. 2011. Glutaminyl cyclase contributes to the formation of focal and diffuse pyroglutamate (pGlu)-A $\beta$ deposits in hippocampus via distinct cellular mechanisms. Acta Neuropathologica 121: 709-719. 
Head, E. 2002. Brain Aging in Dog: parallels with human brain aging and Alzheimer's disease. Journal of Veterinary Pharmacology and Therapeutics 2(3): 247-260.

Head, E. 2008. Oxidative damage and cognitive dysfunction: antioxidant treatments to promote healthy brain aging. Neurochemical Research 34(4): 670-678.

Heath, S.E., Barabas, S., and Craze, P.G. 2007. Nutritional supplementation in cases of canine cognitive dysfunction-a clinical trial. Applied Animal Behaviour Science 105: 274-83.

Inagawa, K., Seki, S., Bannai, M., Takeuchi, Y., Mori, Y., and Takahashi, M. 2005. Alleviate effects of $\gamma$ aminobutyric acid on behavioural abnormalities in aged dogs. The Journal of Veterinary Medical Science 67(10): 1063-1066.

Iwata, N., Higuchi, M., and Saido, T.C. 2005. Metabolism of amyloid- $\beta$ peptide and Alzheimer's disease. Pharmacology and Therapeutics 108: 129-148.

Jaggy, A. 2010. Behavioural problems and abnormal behaviour. In Small Animal Neurology, 467-489, ed. A. Jaggy. Germany: Schlütersche.

Laflamme, D.P. 2012. Nutritional care for aging cats and dogs. Veterinary Clinics of North America-Small Animal Practice 42: 769-791.

Landsberg, G. 2005. Therapeutics agents for the treatment of cognitive dysfunction syndrome in senior dogs. Progress in Neuro-Psychopharmacology and Biological Psychiatry 29: 471-479.

Landsberg, G., DePorter, T., and Araujo, J.A. 2011. Clinical signs and management of anxiety, sleeplessness and cognitive dysfunction in the senior pet. Veterinary Clinics of North America-Small Animal Practice 41: 565-590.

Landsberg, G., Hunthausen, W., and Ackerman, L. 2013. Appendix D Drug dosages. In Behaviour Problems of the Dog and Cat, 415-422, ed. R. Edwards. China: Saunders Elsevier.
Landsberg, G.M., Nichol, J., and Araujo, J.A. 2012. Cognitive dysfunction syndrome. A disease of canine and feline brain aging. Veterinary Clinics of North America-Small Animal Practice 42: 749-768.

Manteca, X. 2011. Nutrition and behavior in senior dogs. Topics in Companion Animal Medicine 26: 33-36.

Mariotti, V.M., Landucci, M., Lippi, I., Amat, M., Manteca, X. and Guidi, G. 2009. Epidemiological study of behavioural disorders in elderly dogs [abstract]. In Proceedings 7 th International Meeting of Veterinary Behaviour Medicine, 241-243, ed. S. E. Heath. Belgium: European Society of Veterinary Clinical Ethology.

Martin, S.B., Cenini, G., Barone, E., Dowling, A.L.S., Mancuso, C., Butterfield, D.A., Murphy, M.P., and Head, E. 2011. Coenzyme Q10 and cognition in atorvastatin treated dogs. Neurosciences Letters 501: 9295.

Milgram, N.W., Landsberg, G.M. and Visnesky, M. 2011. Effect of apoaequroin on cognitive function in aged canines. Paper presented at the 17th Congress of ESVCE "Social communications in companion animals" and 1st Annual Congress of ECAWBM, Avignon, France, November 25-26, 2011.

Nagasawa, M., Shimozawa, A., Mogi, K., and Kikusui, T. 2014. N-acetyl-D-mannosamine treatment alleviates age-related decline in place learning ability in dogs. Journal of Veterinary Medical Science 76: 757-761.

Nelson, R.W. and Couto C.G. 2009. Clinical manifestations of hepatobiliary disease. In Small Animal Internal Medicine, 485-495, ed. R.W. Nelson, C.G. Couto. St, Louis, Missouri: Mosby Elsevier.

Nelson, R.W. and Couto C.G. 2009. Clinical manifestations of urinary disorders. In Small Animal Internal Medicine, 607-622, ed. R.W. Nelson, C.G. Couto. St, Louis, Missouri: Mosby Elsevier.

Nelson, R.W. and Couto C.G. 2009. Disorders of the joints. In Small Animal Internal Medicine, 1127-1141, ed. R.W. Nelson, C.G. Couto. St, Louis, Missouri: Mosby Elsevier.

Nielson, J.C., Hart, B.L., Cliff, K.D., and Ruehl, W.W. 
2001. Prevalence of behavioral changes associated with age-related cognitive impairment in dogs. Journal of the American Veterinary Medical Association 218: 1787-1791

Pan, Y., Larson, B., Araujo, J.A., Lau, W., De Rivera, C., Santana, R., Gore, A., and Milgram, N.W. 2010. Dietary supplementation with medium-chain TAG has longlasting cognition-enhancing effects in aged dogs. British Journal of Nutrition 103: 1746-1754.

Pan, Y. 2011. Enhancing brain function in senior dogs: a new nutritional approach. Topics in Companion Animal Medicine 26: 10-16.

Pugliese, M., Gangitano, C., Ceccariglia, S., Carrasco, J.L., Del Fa, A., Rodríguez, M.J., Michetti, F., Mascort, J., and Mahy, N. 2007. Canine cognitive dysfunction and the cerebellum: acetylcholinesterase reduction, neuronal and glial changes. Brain Research 1139: 85-94.

Reilly, C.E. 2001. Neprilysin content is reduced in Alzheimer brain areas. Journal of Neurology 248: 159-160.

Romanucci, M. and Della Salda, L. 2015. Oxydative stress and protein quality control systems in the aged canine brain as a model for human neurodegenerative disorders. Oxidative Medicine and Cellular Longevity 2015.
Salvin, H.E., McGreevy, P.D., Sachev, P.S., and Valenzuela, M.J. 2006. Under diagnosis of canine cognitive dysfunction; a cross-sectional survey of older companion dogs. Veterinary Journal 184: 277-281.

Schmidt, F., Boltze, J., Jäger, C., Hofmann S., Willems, N., Seeger, J., Härtig, W., and Stolzing, A. 2015. Detection and quantification of $\beta$-amyloid, pyroglutamil $\mathrm{A} \beta$, and tau in aged canines. Journal of Neuropathology and Experimental Neurology 74: 912-923.

Siwak-Tapp, C.T., Head, E., Muggenburg, B.A., Milgram, N.W., and Cotman, C.V. 2007. Neurogenesis decreases with age in the canine hippocampus and correlates with cognitive function. Neurobiology of Learning and Memory 88(2): 249-259.

Taha, A.Y., Henderson, S.T., and Burnham, W.M. 2009. Dietary enrichment with medium chaintriglycerides (AC-1203) elevates polyunsaturated fatty acids in the parietal cortex of aged dogs; implications for treating age-related cognitive decline. Neurochemical Research 34(9): 1619-1625.

Vite, C.H. and Head, E. 2014. Aging in the canine and feline brain. Veterinary Clinics of North America-Small Animal Practice 44: 1113-1129. 